\title{
Pelatihan Pembuatan Nata de coco di Perkebunan Kelapa Desa Margomulyo Kecamatan Seyegan Kabupaten Sleman
}

\author{
Training on making Nata de coco in coconut plantation Margomulyo Village, Sleman \\ Regency
}

\section{Wiwit Probowati* dan Isnin Aulia Ulfah Mu'awanah}

*Universitas 'Aisyiyah Yogyakarta, Jl. Siliwangi No.63 Nogotirto, Gamping Sleman, DIY. e-mail:wiwitprobo@unisayogya.ac.id

\begin{abstract}
Abstrak
Tanaman kelapa merupakan komoditas yang sangat potensial, semua bagian tanaman kelapa bermanfaat bagi kebutuhan hidup manusia. Semua bagian buah kelapa tidak ada yang terbuang dan dapat dimanfaatkan untuk menghasilkan produk industri. Mitra adalah petani kelapa yang menjual kelapa kupas dan daging buah kelapa. Petani di desa Margomulyo ini kesulitan dalam menangani limbah air kelapa yang dibuang percuma menggenangi lahan tanpa dimanfaatkan. Kadang apabila air kelapa ini tidak langsung terserap di tanah akan menimbulkan bau tidak sedap di lingkungan sekitar. Oleh karena itu pemanfaatan air kelapa merupakan cara mengoptimalkan pemanfaatan bagian buah kelapa. Adanya gula sukrosa dalam air kelapa akan dimanfaatkan oleh Acetobacter xylinum sebagai sumber energi, maupun sumber karbon untuk membentuk senyawa metabolit diantaranya adalah selulosa yang membentuk Nata de Coco. Kesimpulan dari pelatihan pembuatan Nata de coco di desa Margomulyo memberikan respons positif bagi warga masyarakat untuk mendirikan unit usaha. Hambatan pelaksanaan kegiatan ini adalah belum ada solusi untuk penanganan limbah produksi Nata de coco yang aromanya cukup mengganggu. Sehingga pelaksanaan program pengolahan limbah nata de coco akan diatasi pada pelaksanaan program pengabdian masyarakat periode selanjutnya.
\end{abstract}

Kata kunci: Pelatihan, kelapa, nata de coco, desa Margomulyo

\section{Abstract}

Coconut plants are very potential commodities, all parts of the coconut plant are beneficial to the needs of human life. All parts of coconuts are not wasted and can be used to produce industrial products. The partners are coconut farmers who sell peeled coconut and coconut flesh. Farmers in Margomulyo village have difficulty in handling the waste of untreated coconut water. Sometimes the coconut water causes inundated land without being used. Sometimes when the coconut water is not directly absorbed in the ground, it will cause bad odor in the environment. Therefore, the use of coconut water is a way to optimize the use of coconut fruit. The content of sucrose sugar in coconut water will be used by Acetobacter xylinum as a source of energy, as well as a carbon source to form metabolite compounds such as cellulose that form Nata de Coco. In conclusion, Nata de coco making training in Margomulyo village gave positive response for the community to establish business unit. The barrier to the implementation of this activity was that there was no solution for handling waste production of Nata de coco of which aroma was quite disturbing. Thus, the implementation of nata de coco waste treatment program will be overcomed in further implementation of community service program which will be held in the next period.

Key words: training, coconut, nata de coco, Margomulyo village 


\section{PENDAHULUAN}

Tanaman kelapa merupakan komoditas yang sangat potensial, semua bagian tanaman kelapa bermanfaat bagi kebutuhan hidup manusia. Buah kelapa terdiri dari sabut, tempurung, daging buah, dan air kelapa. Semua bagian buah kelapa tidak ada yang terbuang dan dapat dimanfaatkan untuk menghasilkan produk industri. Sabut kelapa dapat dimanfaatkan sebagai fibre, keset, sapu, jok mobil, dan matras. Daging buah dapat dipakai sebagai bahan baku untuk menghasilkan kopra, minyak kelapa, coconut cream, santan, dan kelapa parutan kering (desiccated coconut), sedangkan air kelapa dapat dipakai untuk membuat cuka, dan nata de coco. Tempurung dapat dimanfaatkan untuk membuat charcoal, karbon aktif, asap cair, dan kerajinan tangan. Dari batang kelapa dapat dihasilkan bahan-bahan bangunan baik untuk kerangka bangunan maupun untuk dinding serta atap, dan peralatan rumah tangga (pot, mebel, dan lain-lain). Daun kelapa dapat diambil lidinya yang dapat dipakai sebagai sapu, serta barangbarang anyaman (Patty, 2011).

Menurut Pearce dan Robinson (2013), selama ini komoditas kelapa baru sebatas dimanfaatkan pada produk primernya saja dalam bentuk kelapa segar maupun kopra untuk bahan baku minyak goreng. Program diversifikasi kelapa Indonesia baru mampu menghasilkan 22 ragam produk turunan kelapa. Angka ini masih jauh di bawah Filipina yang telah memproduksi lebih dari 100 jenis diversifikasi produk berbasis kelapa. Hasil samping dan limbah belum dimanfaatkan secara optimal, sehingga belum dapat dihasilkan nilai tambah yang berarti secara ekonomi, baik di tingkat petani maupun di tingkat pengusaha.

Salah satu diversifikasi kelapa yang dikembangkan di Indonesia adalah Nata de Coco. Nata de Coco merupakan nama produk olahan yang dibuat dari air kelapa dengan bantuan bakteri Acetobacter xylinum. Nata de Coco adalah bahan padat seperti agar-agar tetapi lebih kenyal atau seperti kolang-kaling, tidak lembek, berwarna putih transparan (Astawan, 2014). Sejenis makanan penyegar atau pencuci mulut dan dapat dicampur ke dalam es krim, fruit coctail, yogurt dan sebagainya (Sihmawati dkk, 2014). Air kelapa adalah bahan baku utama pembuatan Nata de Coco, sebaliknya air kelapa yang digunakan berasal dari buah kelapa hijau yang matang. Air kelapa yang digunakan harus murni tidak bercampur dengan air maupun kotoran, namun tidak harus selalu dalam keadaan segar (air kelapa baru). Air kelapa mengandung berbagai nutrisi yang bisa dimanfaatkan bakteri penghasil Nata de Coco. Nutrisi yang terkandung dalam air kelapa antara lain : gula sukrosa $1,28 \%$, sumber mineral yang beragam antara lain Magnesium serta adanya faktor pendukung pertumbuhan (growth promoting factor), merupakan senyawa yang mampu meningkatkan pertumbuhan bakteri penghasil nata (Acetobacter xylinum). Adanya gula sukrosa dalam air kelapa akan dimanfaatkan oleh Acetobacter xylinum sebagai sumber energi, maupun sumber karbon untuk membentuk senyawa metabolit diantaranya adalah selulosa yang membentuk Nata de Coco (Lehninger, 1996).

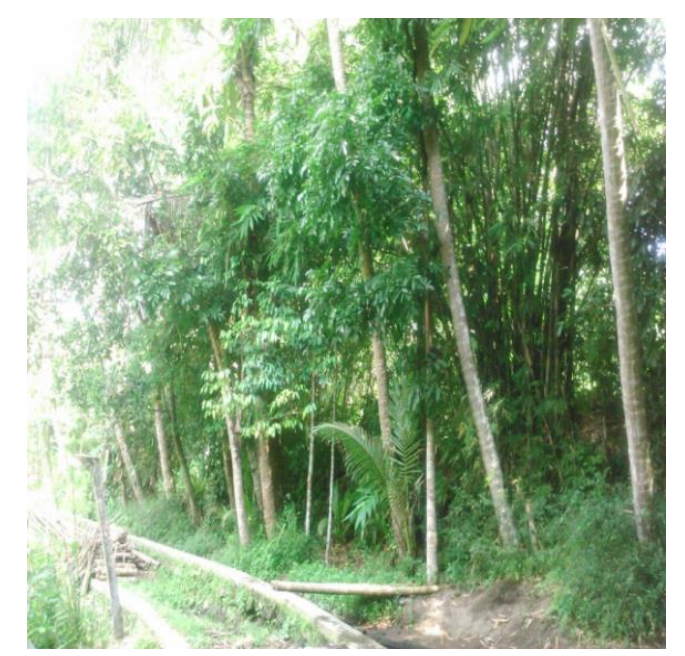

Gambar 1. Perkebunan di desa Margomulyo milik warga 


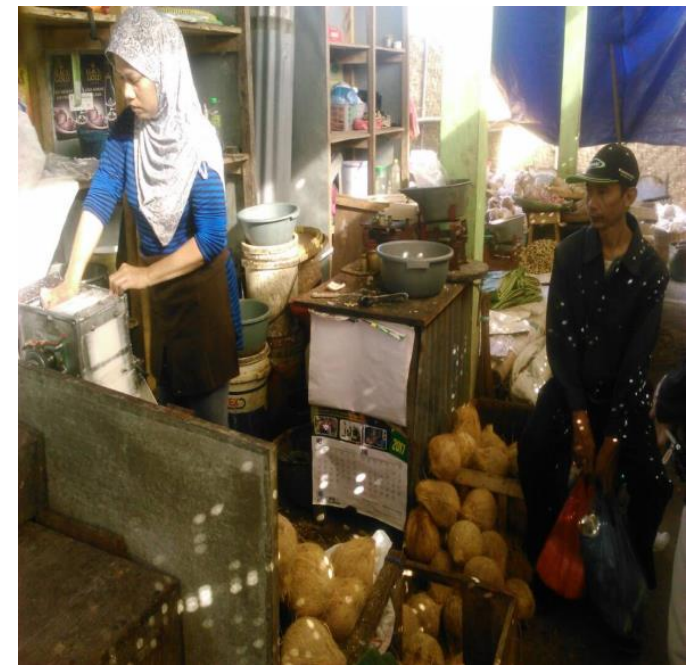

Gambar 2. Penjualan kelapa kupas dan kelapa parut di pasar Cebongan, Sleman

Data BPS Kabupaten Sleman tahun 2015, menunjukkan bahwa tanaman kelapa masih menjadi tanaman unggulan di daerah ini, dengan luas areal perkebunan kelapa mencapai 61.143,65 hektar dengan produksi $\pm 83.379,60$ ton per tahun, dan jumlah petani kelapa yang mencapai 36.112 kepala keluarga. Luasnya perkebunan kelapa di daerah ini karena tanaman kelapa (Cocos nucifera. Linn) memang sudah lama dikenal di daerah Seyegan, sejak diintroduksi sekitar awal abad 19 yang lalu. Potensi kelapa di atas, harusnya menjadi potensi yang luar biasa yang dapat dikembangkan bagi peningkatan ekonomi masyarakat. Namun sayangnya kondisi yang terjadi adalah potensi yang ada belum dapat dimanfaatkan secara maksimal sehingga belum mampu melepaskan masyarakat dari kondisi kemiskinan, yang sampai saat ini masih cukup memprihatinkan.

Desa Margomulyo adalah sebuah desa di kecamatan Seyegan yang mayoritas penduduknya berprofesi sebagai petani. Menurut data statistik kabupaten Sleman tahun 2015 menunjukkan bahwa 60\% penduduk bekerja sebagai petani, 20\% sebagai pengrajin bambu dan sisanya ada yang menjadi pegawai dan pedagang. Pertanian yang paling banyak di desa Margomulyo adalah kelapa. Petani yang kami pilih sebagai calon pengusaha dalam program kemitraan ini adalah petani yang memiliki luas kebun kelapa terluas di desa Margomulyo. Petani tersebut setiap harinya menjual $10 \mathrm{Kg}$ daging buah kelapa kupas atau kelapa kupas yang dijual ke pasar terdekat.

Dalam Program Kemitraan Masyarakat ini nilai tambah kelapa diartikan sebagai peningkatan nilai pengolahan kelapa menjadi produk lain, yang diperoleh dari selisih nilai output dengan nilai input yang dihitung dalam $\mathrm{Rp} / \mathrm{kg}$ produk yang dihasilkan, dinyatakan dalam rupiah per kilogram (Rp/kg). Nilai output adalah hasil kali jumlah produksi dengan harga produk dikalikan dengan jumlah produksi kemudian dibagi dengan jumlah input kelapa, sedangkan nilai input itu sendiri adalah jumlah biaya kelapa ditambah biaya penolong, kemudian dibagi dengan jumlah input kelapa (Prihatiyani, 2016). Kondisi yang telah diuraikan diatas dianggap perlu mendapat perhatian berbagai pihak terutama pemerintah daerah dan perguruan tinggi setempat untuk mengkaji lebih jauh berbagai hal yang terkait dengan produktivitas kelapa rakyat dan nilai tambah yang diterima petani kelapa dari pengolahan yang dilakukan selama ini yang hanya sebagai kelapa utuh (Sutarminingsih, 2010). Untuk itu dilakukan suatu program kemitraan yang bertujuan untuk: (1) mengetahui produktifitas kelapa rakyat (2) meningkatkan nilai tambah kelapa dengan pembuatan produk Nata de coco

\section{SOLUSI/TEKNOLOGI}

Dari permasalahan yang dihadapi mitra maka solusi yang ditawarkan dari Program Kemitraan Masyarakat ini sebagai berikut:

1. Penyuluhan mengenai prospek usaha lain selain berkebun dan penjualan kelapa utuh. Kami mencoba member gambaran tentang perdagangan dari produk olahan air kelapa.

2. Melatih mitra untuk mengolah air kelapa untuk difermentasi menjadi Nata de coco. Bioteknologi sederhana 
dengan pemanfaatan bakteri Acetobacter xyllinum yang mampu memanfaatkan glukosa dalam metabolismenya menjadi serat-serat selulosa pembentuk lembaran nata.

3. Pelatihan pengolahan produk Nata de coco menjadi minuman Nata De coco.

\section{HASIL DAN DISKUSI}

Bibit atau starter merupakan suatu populasi mikroba dalam jumlah dan kondisi fisiologis yang siap diinokulasikan pada media fermentasi. Mikroba pada starter tumbuh dengan cepat dan fermentasi segera terjadi. Dalam industry nata de coco, Pembuatan bibit nata de coco dimaksudkan untuk memperbanyak jumlah bakteri pembentuk nata yaitu Acetobacter xylinum yang dimanfaatkan untuk membantu fermentasi air kelapa. Pembuatan bibit nata biasanya dalam jumlah yang cukup banyak dan disimpan dalam botol transparan (Pambayun, 2012).

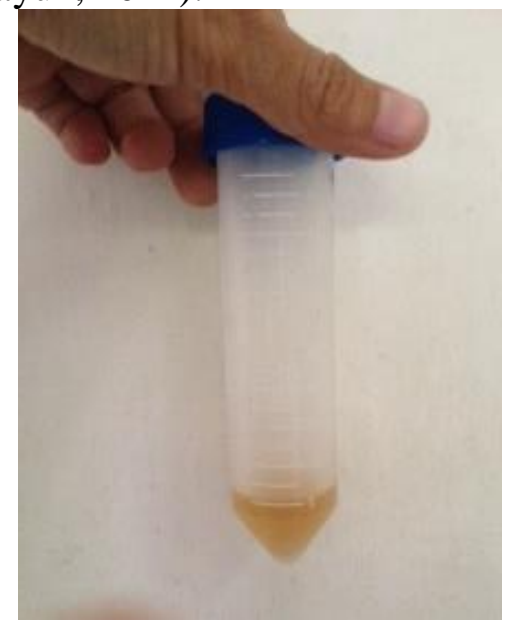

Gambar 3. Bibit nata murni yang berisi kultur Acetobacter xyllinum yang digunakan untuk fermentasi air kelapa

Air kelapa yang telah diambil dari buahnya direbus dalam panci kemudian ditambahkan gula pasir, cuka dan pupuk ZA. Komposisinya mengikuti cara kerja yang telah dipaparkan sebelumnya. Hasil perebusan ini merupakan media yang selanjutnya akan digunakan oleh bakteri Acetobacter xyllinum hidup dan berkembang biak. Media ini didinginkan sampai suhu kamar untuk selanjutnya dapat diberi kultur bakteri (bibit nata).

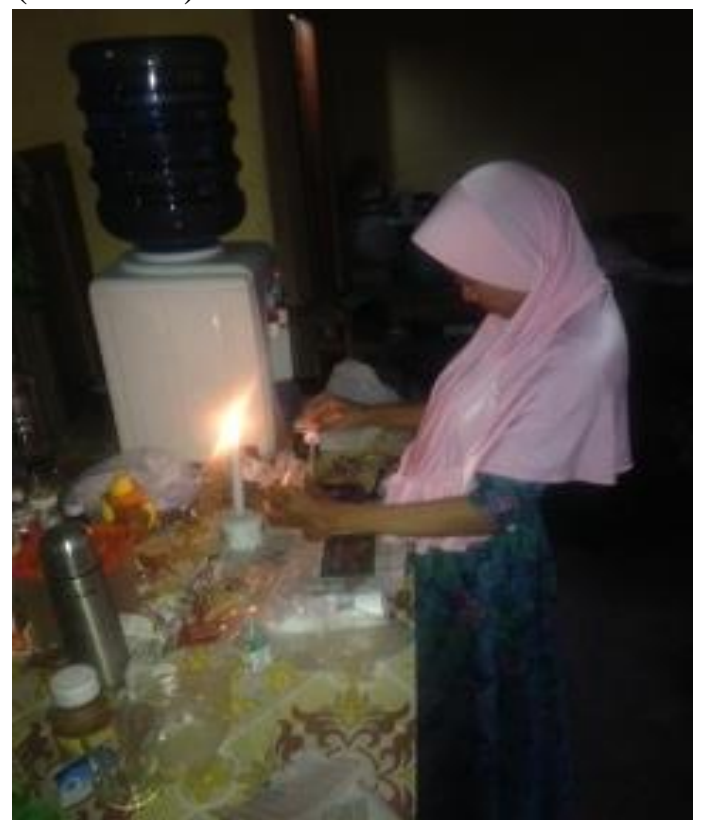

Gambar 4. Proses pemberian bibit nata pada media yang sudah direbus

Media yang telah diberi bibit nata selanjutnya difermentasi selama 1 minggu untuk mendapatkan hasil bibit nata. Proses ini sebenarnya adalah prses pencairan bibit nata dari yang masih murni menjadi lebih rendah konsentrasinya atau lebih banyak starternya. Bibit nata yang sudah encer ini selanjutnya dapat diencerkan lagi untuk kapasistas air kelapa yang lebih banyak.

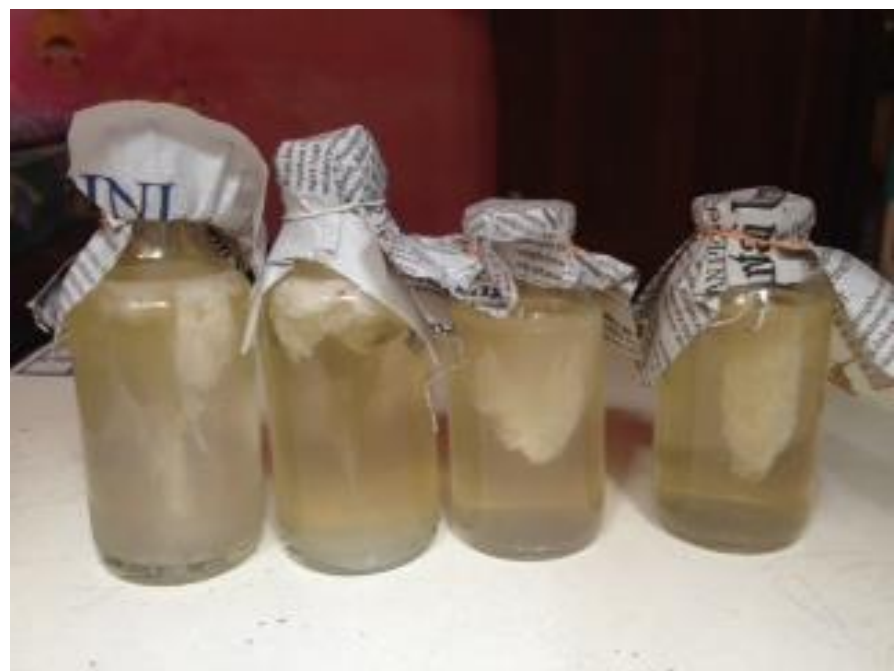

Gambar 5. Nata yang terbentuk dari media air kelapa yang telah diberi bibit nata murni 


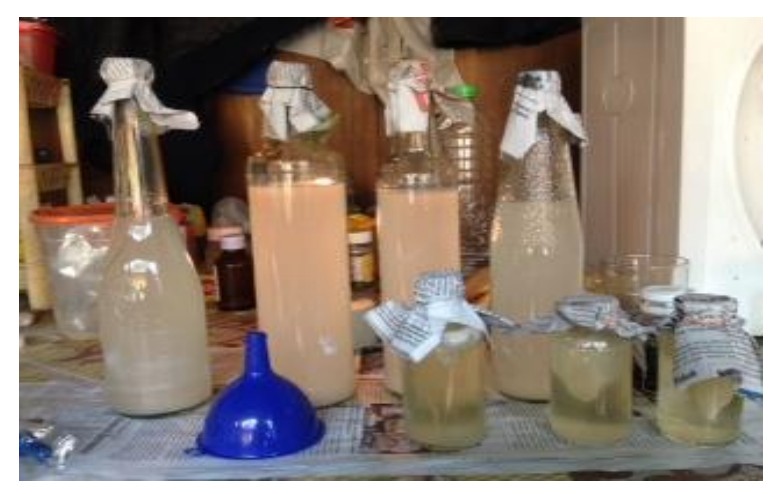

Gamar 6. Bibit nata berukuran 1 Lter yang siap dituang ke midia dalam baki

Pembentukan nata de coco pada saat pengenceran media sudah ada yang menunjukkan keberhasilan pembuatan media. Nata terbentuk di bagian atas botol media, walaupun kecil tetapi itu sudah menunjukkan keberhasilan proses fermentasi bakteri. Pengenceran media dari bibit murni ke media tingkat 1 berlangsung selama 1 minggu kemudian pengenceran berikutnya juga membutuhkan waktu kurang lebih 1 minggu. Setelah didapatkan media 1 liter dalam botol sirup, maka pelatihan pembuatan nata de coco Bersama warga siap dilakukan.

Pelatihan pembuatan nata de coco dilaksanaan di rumah kepala dusun Kamal wetan yang bersedia menerima warga untuk berlatih membuat nata de coco. Peserta pelatihan adalah warga desa Margomulyo yang didata mempunyai lahan perkebunan kelapa. Selain itu warga juga tertarik untuk mengikuti pelatihan ini.

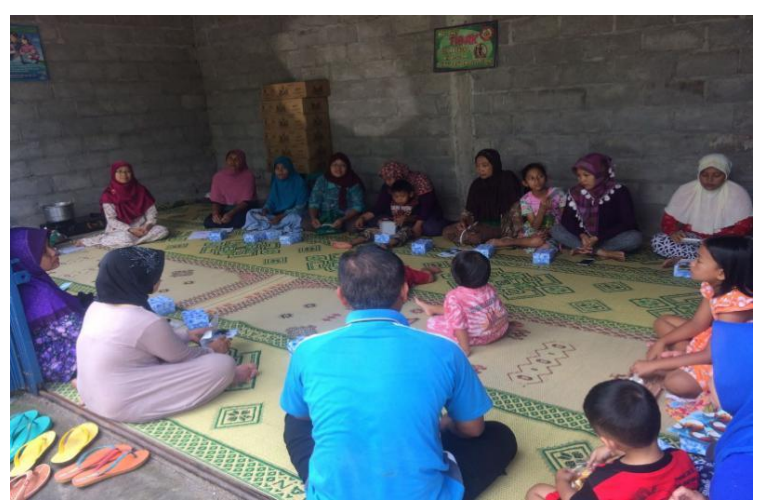

Gambar 7. Sambutan kepala dusun Kamal wetan dalam acara pelatihan pembuatan nata de coco
Pelatihan pembuatan nata de coco berlangsung 1 hari penuh mulai dari pembuatan media nata dengan merebus air kelapa yang ditambahkan gula pasir, cuka dan pupuk ZA kemudian sampai penuangan media nata ke baki-baki fermentasi. Setelah penuangan media nata ke dalam baki kemudian media ini difermentasi selama 2 minggu sampai terbentuk lembaran nata.

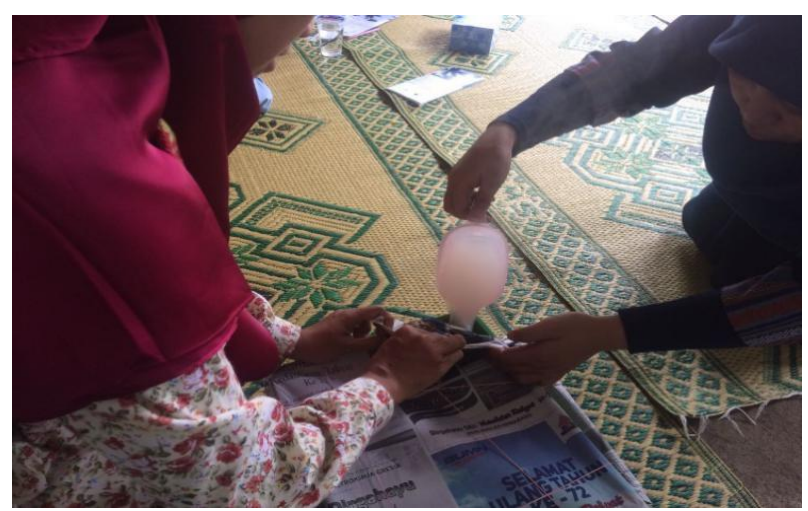

Gambar 8. Penuangan media nata ke dalam baki fermentasi

Proses fermentasi dilakukan secara aerob namun dalam kondisi minim cahaya dan sirkulasi udara baik. Baki-baki ini disimpan dalam ruangan yang redup dan sirkulasi udara baik atau tidak banyak angin. Feremntasi dilakukan sampai dua minggu kemudian dilakukan pengecekan pembentukan nata dalam baki atau nampan.

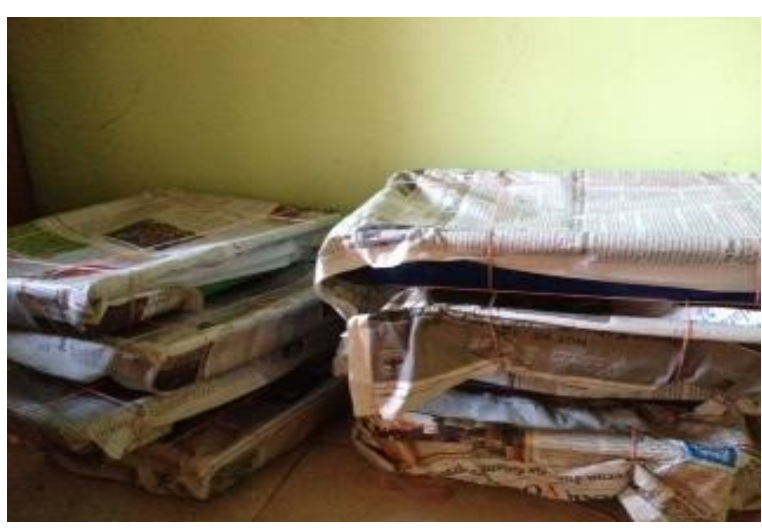

Gambar 9. Baki-baki yang berisi media nata siap fermentasi selama dua minggu

Volume media yang ditungkan kurang lebih 1 liter atau sampai baki terisi media setebal $1 \mathrm{~cm}$. harapannya nata yang 
terbentuk tidak terlalu tebal sehingga mudah untuk diiris. Baki fermentasi ditutup rapat dengan koran agar udara tidak terlalu banyak masuk yang mungkin dapat mengkontaminasi media. Setelah menunggu selama 2 minggu baki-ini dapat dibuka dan dilihat keberhasilan pembentukan nata de coco.

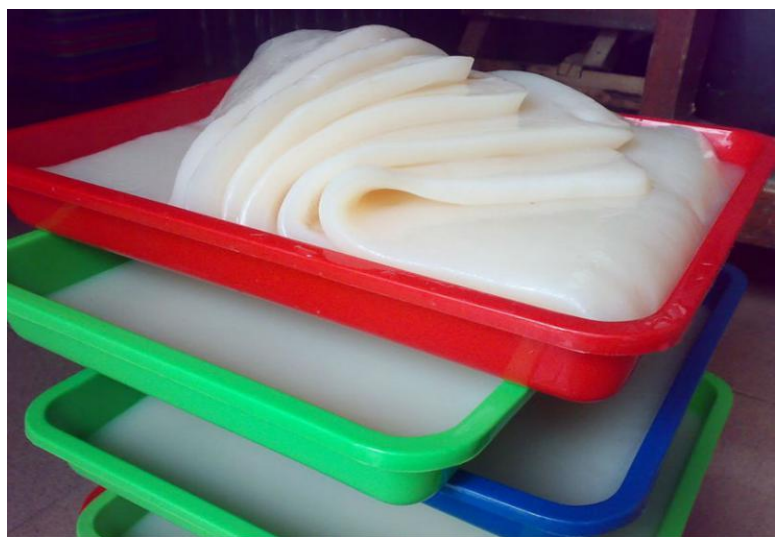

Gambar 10. Lembaran nata de coco yang terbentuk setelah 2 minggu

Setelah 2 minggu baki dibuka dan dilihat keberhasilan pembbentukan nata. Dari hasil pelatihan tersebut didapatkan lembaran-lembarn nata de coco berwarna putih setebal kurang lebih $1 \mathrm{~cm}$ dan kenyal. Lembaran-lembaran nata ini selanjutnya dapat langsung diproses untuk diolah menjadi minuman nata de coco atau disimpan sebagai stok. Cara penyiapannya cukup dengan mencuci berulang kali sampai bau ureanya hilang. Kemudian dapat dipotong-potong dan direbus untuk dibuat minuman nata dan bisa ditambahkan sirup buah.

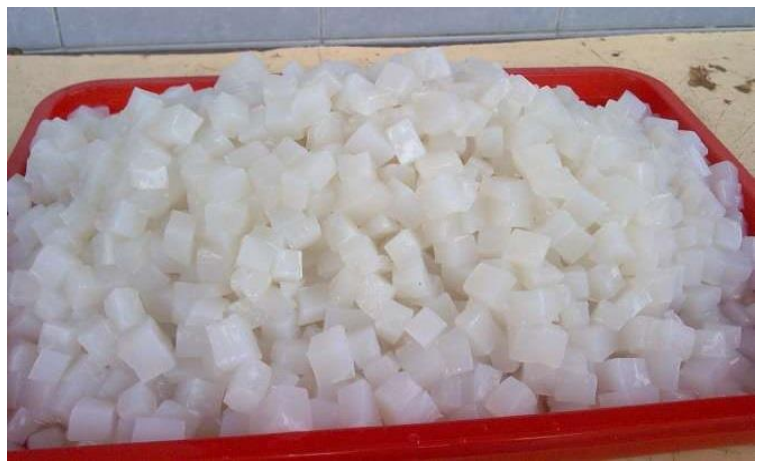

Gambar 11. Nata de coco yang sudah dipotong-potong dadu siap direbus dan dibuat minuman segar
Adanya penyuluhan tentang penmbuatan nata de coco dari air kelapa sangat berguna untuk warga petani kelapa desa Margomulyo. Karena pengetahuan pembuatan nata de coco ini baru ada dan dilakukan oleh pihak akademisi. Dari dinas industri atau pemerintah belum ada yang melakukan penyuluhan dan pelatihan seperti ini. Pelatihan pembuatan nata de coco yang dilakukan dengan praktek langsung juga sangat bermanfaat untuk melatih ketrampilan warga yang bisa diterapkan ketika mereka akan membuka usaha.

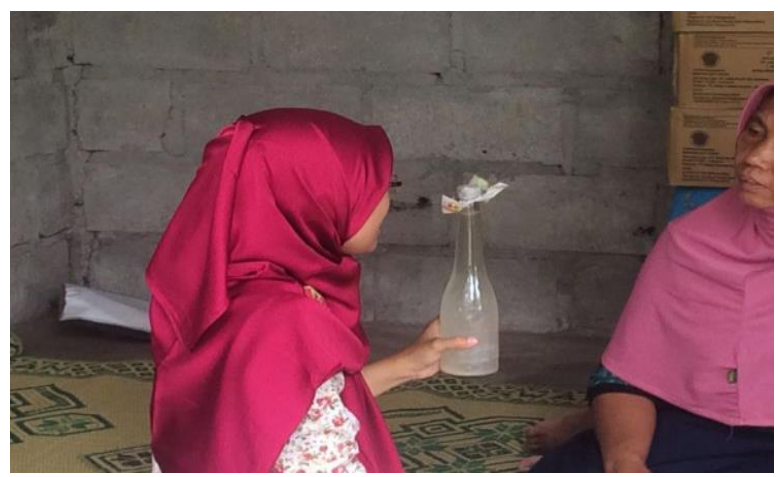

Gambar 12. Antusiasme warga yang bertanya tentang cara pembuatan nata de coco

Akhir dari kegiatan penyuluhan dan pelatihan ini adalah mengolah hasil lembaran nata de coco yang dimasak dan dibuat minuman nata de coco yang segar kemudian disantap bersama warga peserta penyuluhan. Rasa nata de coco yang kenyal dan segar apabila ditambahkan sirup buah membuat minuman ini cocok disantap di kala cuaca terik.

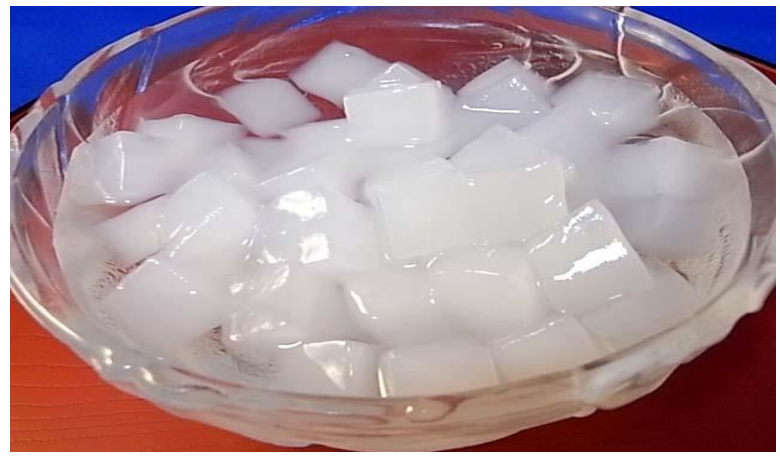

Gambar 13. Minuman nata de coco yang siap disantap 
Secara garis besar warga petani kelapa desa Margomulyo antusias dan puas akan adanya penyuluhan dan pelatihan pembuatan nata de coco. Warga mendapatkan pengetahuan baru dan ketrampilan yang dapat dipraktekkan untuk berwirausaha. Satu-satunya kendala untuk membuka usaha industri nata de coco adalah ketersediaan bibit murni nata de coco yang belum terbuka di pasaran..

\section{KESIMPULAN}

1. Kegiatan pengabdian masyarakat ini dapat dibagi menjadi 3 proses, yaitu persiapan, pelaksanaan penyuluhan dan pelatihan, serta proses pendampingan mitra.

2. Pihak mitra, terutama petani kelapa warga desa Margomulyo, memperoleh wawasan mengenai potensi air kelapa yang dapat menghasilkan produk yang dapat dipasarkan sehingga warga dapat berwirausaha.

Peserta penyuluhan dan pelatihan mendapatkan pengetahuan secara langsung tentang cara pembuatan nata de coco, sehingga bisa dipraktekkan di rumah maupun untuk skala indusri rumah tangga.yang menyatakan kegiatan PkM yang perlu dilanjutkan.

\section{UCAPAN TERIMA KASIH}

Kami mengucapkan terima kasih kepada Lembaga Penelitian dan Pengabdian kepada Masyarakat UNISA atas difasilitasinya pelaksanaan pengabdian masyarakat ini melalui hibah internal LPPM UNISA pengabdian masyarakat.

\section{PUSTAKA}

Astawan. M. 2014. Nata De Coco yang Kaya Serat. Kompas. http://www.ristek.go.id diakses tanggal 31 Agustus 2017
Biro Pusat Statistik. 2015. Kabupaten Sleman dalam Angka. BPS Kabupaten Sleman.DIY

Hakimi, Rini dan Daddy Budiman. 2006. Aplikasi Produksi Bersih (Cleaner Production) pada Industri Nata De Coco. Jurnal Teknik Mesin. 3 (2) 9098.

Lehninger, A.A. 1996. Pengantar Biokimia. Gajah Mada University Press. Yogyakarta.

Pambayun, R. 2012. Teknologi pengolahan nata de coco. Kanisius. Yogyakarta.

Patty, Zeth. 2011. Analisis Produktivitas dan Nilai Tambah Kelapa Rakyat. Jurnal Agroforestri Volume VI Nomor 2 Juni 2011. ISSN : 1907-7556

Pearce, J.A dan R.B. Robinson. 2013. Manajemen Strategi, Formulasi, Implementasi dan Pengendalian (Terjemahan, Jilid I). Bina Rupa Aksara, Jakarta.

Prihtiyani. E. 2016. Perkebunan, Komoditas Kelapa yang Terabaikan. http://www.deptan.go.id.diakses 15 Februari 2017

Sihmawati, Oktoviani dan Wardah. 2014. Aspek Mutu Produk Nata de coco dengan Penambahan sari buah mangga. UNTAG Surabaya Jurnal Teknik Industri HEURISTIC 11 (2): 1693-8232

Sutarminingsih.L. 2010.Peluang Usaha Nata de Coco. Kanisius. Yogyakarta.

Warsiati, et al. 2013. Pemanfaatan Limbah Air Kelapa Menjadi Produk Coco Cider : Kajian Penambahan Gula Dan Waktu Fermentasi. Jurnal Bumi Lestari, 13 (1), Febuari 2013. Agustina E., Andiarna, F., Lusiana, N., Purnamasari, R., Hadi, M. I. (2018). Identifikasi Senyawa Aktif dari Ekstrak Daun Jambu Air (Syzygium aqueum) dengan Perbandingan Beberapa Pelarut pada Metode Maserasi. Biotropic, 2(2), 108-118. DOI:

10.29080/biotropic.2018.2.2.108118. 